\title{
Title:
}

“An Investigation of Pivotal Moments in Music Therapy in Adult Mental Health"

\section{Authors' Details:}

Maria Gavrielidou, MA (Corresponding Author) Anglia Ruskin University, East Road, Cambridge, CB1 1PT, UK

Present Address: Bodenbacher Straße 85c, 01277 Dresden, Deutschland Email: mariagavrielidou5@gmail.com

Tel.: 004917680649892 / 0035799536992

\section{Helen Odell-Miller, $\mathrm{PhD}$ (Co-Author)}

Music Therapy Research Centre, Anglia Ruskin University, Cambridge, UK Address: Anglia Ruskin University, East Road, Cambridge, CB1 1PT, UK

Email: helen.odell-miller@anglia.ac.uk 


\begin{abstract}
This article describes a study that investigated pivotal moments in music therapy in adult mental health settings. A phenomenological qualitative method was used in order to search for answers to the questions for investigation. It included an extensive literature review, regarding pivotal moments from different fields, including music therapy. Three semi-structured interviews with music therapists investigated their experience of pivotal moments, the role function and importance of pivotal moments in music therapy. Detailed information was analysed using Phenomenological Interpretative Analysis (IPA). A case study supports the evidence gathered in the interviews and literature review, and describes the emergence of a pivotal moment and its contribution within a short-term individual music therapy treatment with a man with schizophrenia. Gathered information and results from the interview analysis highlight distinctive characteristics of pivotal moments and their contribution to the patients' lives and therapists' work. Pivotal moments are found to change the music therapy process and lead to a better understanding of the patient. The role of the therapist, the therapist's qualities and basic features or techniques that support the emergence of pivotal moments, are also discussed.
\end{abstract}

\title{
Keywords
}

music therapy; pivotal moments; schizophrenia; mental health 
This study investigates pivotal moments in music therapy in adult mental health settings with specific reference to schizophrenia. The purpose is to gain a deeper understanding of the experience of pivotal moments in music therapy, adding to existing knowledge on this subject. In particular the qualitative research contributes to the more substantial quantitative research referred to in the Cochrane review (Gold, Heldal, Dahle, and Wigram, 2005). The study was conducted as part of a dissertation, which was submitted in April 2014 in partial fulfilment of the requirements of (Name of the University) University for the Degree of Master in Music Therapy. (Name of the co-author), co-author, was the research supervisor of the study; (Name of the corresponding author) is the music therapist who undertook the study. (Name of the corresponding author) will be referred to as "music therapist" in the cases where the clinical work is described, along with personal ideas and reflection.

Pivotal moments are significant, because they appear to transform aspects of a person's life in a meaningful way. As the researcher-music therapist has experienced situations where her music had a pivotal role in another person's life both within as well as outside the therapeutic setting, she became aware of the significance of these moments, and therefore she was more intrigued and motivated to further investigate the occurrence of pivotal moments through the study. We defined the term as follows: "Pivotal moments describe a turning point, a moment of pivoting, or change, where something is seen from a different perspective or point of view and seem to be significant and nodal for the person involved". The term pivotal moments suggests a quality of experience, which is very powerful and meaningful for the person involved (e.g. the patient), in provoking change.

As the aim of the study was to investigate the occurrence of pivotal moments with people with a mental illness, we based the study on a phenomenological qualitative approach (Ashworth, 2003; Giorgi and Giorgi, 2008; Lawthom and Tindall, 2011), a design appropriate to deal with the main questions for investigation. This approach offered us the opportunity to collect data from different fields and points of view. It was initially very important to understand the key-terms used to describe pivotal moments and similar kinds of experiences, and then to relate them to real life examples. As the study included a single case study, of a man with schizophrenia, the music therapist also conducted semi-structured interviews to strengthen the data. This enabled us to collect experiences from other music therapists working in mental health using a purposeful sample. 


\section{Music Therapy in Mental Health}

People with serious mental health problems, and specifically schizophrenia, may often experience difficulties in emotional responsiveness and social interaction; and may lack motivation for verbal therapies. Schizophrenia is defined as a severe mental health problem by DSM-5 (2013) and according to the World Health Organisation (WHO, 2016) schizophrenia affects about 21 million people worldwide. Moreover, the Schizophrenia Research Institute (2013) states that schizophrenia is a major cause of suicide and people with schizophrenia have 2.5 times the death rate of the general population. For these reasons also we focussed on this population, as previous studies show progress in social functioning, global and mental state (Gold, 2007; Gold, Solli, Krüger, \& Lie, 2009; Mohammadi, Minhas, Haidari, \& Pannah, 2012). Furthermore, The National Institute for Clinical of Excellence guidelines for schizophrenia (NICE, 2014) recommend that arts therapies are beneficial in the alleviation of negative symptoms and recommend offering arts therapies in promoting recovery. Music therapy is further acknowledged in the Recovery approach in mental health, including schizophrenia (Jampel, 2006; McCaffrey, Edwards, \& Fannon, 2011). Case reports show that music therapy as a supportive intervention is able to meet individuals at their level of functioning and build on strengths for a meaningful life, beyond the symptomatology or illness.

Music therapy for people with schizophrenia also facilitates the possibilities of creating a containing and supporting environment, where the conditions for change are enhanced and symptoms such as lack of motivation and isolation can particularly be addressed (Mössler, Assmus, Heldal, Fuchs, \& Gold, 2012; Odell-Miller, 2001; Carr, Odell-Miller and Priebe, 2013). Music therapy is sometimes used as a diagnostic tool, but recent research mainly confirms previous clinical findings (Odell-Miller, 1991; Unkefer, 1990), that music therapy is suitable for the treatment for people with psychiatric illness (Pedersen, 2014). Effectiveness of music therapy in the field of psychiatry has also been anecdotally linked to cognitive and communication improvement, and social and emotional rehabilitation (Pedersen, 1999; Solanki, Zafar, \& Rastogi, 2013; Van Camp, 1999).

According to Pedersen (2014), the reasons for positive treatment outcome with people who have schizophrenia are related to music therapists' overall attitudes and relational competencies. These also contribute to quality of life and resources for these patients. As therapists guide their patients in discovering themselves, pivotal 
moments are very significant within a therapeutic context, as they are crucial for change and the therapeutic process. Therefore, a better understanding of pivotal moments will enable the therapists to create an environment where the conditions are encouraging and supportive for their patients' experience. It is for these reasons that the authors decided to explore further and examine pivotal moments in music therapy.

\section{Defining the Key Terms}

According to the Longman Dictionary of Contemporary English (2009), pivot is defined as a central point on which something balances or turns or as the most important thing in a situation. In this study, the words pivot and pivotal have been used in reference to the quality or significance of an experience for the person involved, as it is highlighted in the second definition. The word moment comes from the Latin "momentum", which in terms of time can be translated as a "very brief portion of time of importance" (Oxford Dictionary Online). For the purpose of the study the term moments was not used as a defined period of physical time, but it represented a time period, which includes a particular quality of experience. The term pivotal moments has been chosen to describe a turning point, a moment of pivoting or change, where something is seen from a different perspective or point of view and seems to be significant and nodal for the person involved.

\section{Pivotal Moments in Music Therapy}

The concept of time is central to the discussion about pivotal moments in music therapy, as it both provides the physical timeframe of the therapy, as well as the psychological/emotional sense to the therapeutic experience. Aldridge (1996) provides a description of time experience on three levels. The first level is chronos, which was developed from a modern industrialised society as a quantitative measurement, in terms of physical time. The second level of time refers to kairos, the Greek word for the moment of something coming into being (Stern, 2004). Kairos is defined as self-emergent and is both a subjective and psychological unit of time. A third type of time, qualitatively different from chronos and kairos time is primarily defined through experience: it is described as being evident only during certain circumstances, including ritual, sex, prayer, contemplation and dancing. During these activities often the perception of time duration is altered, influenced by the intensity 
and the emotional impact of the experience. Aldridge's (1996) conception of time is close to our definition of pivotal moments.

Robbins and Forinash (1991) describe a model of time phenomena within music therapy they call the time paradigm. Within this model they describe experiences in which time seems suspended while the therapist and patient are engaged in musical and emotional sharing. During this process a "moment of intuition, perception, sudden insight or understanding" (p. 53) occurs, similar to a pivotal moment.

This model also links to Priestley's $(1975,1994)$ earlier description of time. She specifically describes two sorts of time: "the passing time in which we hurry along to our next pay-day, for example, and the Eternal Now where we stand still and wonder" (1994, p. 321). In Priestley's (1975) opinion, during the Eternal Now time the individual is enabled to undergo a transformation process, while physical time is often altered in the way it is perceived. This process of Eternal Now is also similar to the concept of a pivotal moment. Grocke's (1999a) research into pivotal moments in her work in Guided Imagery and Music, also highlights the possibility of time altering experiences for the patient and therapist within music therapy.

It is also considered vital to acknowledge the therapist's capacity to deal with 'here and now' in music therapy. Odell-Miller (2002) describes the long-term span of years during a music therapy treatment, for adults with severe mental health problems and short term specifically timed moments of improvisations within each session. Highlighting the importance of 'here and now' interactions, this also reflects internal and external timeframes. Pedersen (1999) also emphasises the importance of these phenomena, in order to unfold and develop meaning in the longer-term relationships.

Further, literature on pivotal moments in music therapy includes a variety of terminology used to label these moments. The term pivotal moments is used by Grocke (1999a, 1999b, 1999c, 2005) to describe the turning points in the client's therapy in her clinical work in Guided Imagery and Music (GIM). During pivotal moments, the patient understands an issue or problem from another perspective and in GIM these are defined as: a) emotional experiences; b) embodied experiences; and c) experiences that impacted on a client's life (Marr, 2001; Lin et al., 2010). Using a phenomenological method of qualitative inquiry, Grocke studied how selections of pre-recorded classical music, chosen by the therapist, lead the clients in a deeply relaxed state, where they experience moments of insight into their therapeutic process 
or their understanding of themselves. Grocke discovered that negative emotions, such as fear and anger, could also be experienced within pivotal moments. Interestingly Grocke, through musical analysis, found that pieces with a structured musical form were the most dominant in the list of music that underpinned pivotal moments, as they provided “a safe 'container' for the experience" (Grocke, 1999c, p. 207).

Amir (1992, 1996, 1999, 2001), in her study on meaningful moments in music therapy, interviewed music therapists and clients, identifying 15 meaningful moments in the experience that related to interpersonal and intrapersonal elements. Meaningful moments of transformation were those in which "clients experienced a powerful insight that virtually changed their lives" (Amir, 1992, p. 92). The term meaningful moments of insight and communication between therapist and client, is also used by Fachner (2014), in order to document and explain changes in, and outcomes of, music therapeutic work, in social neuroscience research.

Moreover, Ruud (1998) compares meaningful moments in music therapy improvisation to Daniel Stern's theory of the present moment in psychotherapy. He concludes that these types of moments may help therapists to understand how improvisational music therapy may lead people to change. Trondalen (2005), who studied significant moments in music therapy with patients suffering from anorexia nervosa, describes how she experiences heightened states of arousal during clinical musical improvisation. She concludes, similarly to Grocke (1999c), that during significant moments the music had a predictable form. Trondalen's study (2005) focuses upon the steady/predictable pulse and intense and condensed dynamics as a trigger or powerful aspect of significant moments. However it does not include harmony.

Pedersen (2006) studied how countertransference is being used as a clinical concept by music therapists working with musical improvisation in adult psychiatry. In her phenomenological study, she investigated 4 music therapists' significant moments in relation to countertransference moments. She uses the term moment of countertransference to identify moments in body feelings, emotions, and in changes in the musical improvisation, which have been as an active part of the countertransference experience and link into the larger context of the therapy process.

De Backer (2008) researched the transition from "sensorial play" to musical form by psychotic patients. He uses the term moments of synchronicity to describe points in time where there is a shared inner experience of the patient and the therapist, in which 
they both feel free and autonomous in their play during a musical improvisation. This shared experience appears unexpectedly and unintentionally, and it is of great importance in music therapy. De Backer's (2008) research showed that music therapy could offer psychotic patients an opportunity for the creation of a certain psychic space, which can create the possibility for a certain degree of potential symbolisation.

Ansdell et al. (2010), as Ruud (1998), also uses Stern's theories to explain therapeutic change in episodes, especially through musical improvisation with psychotic patients. He concludes that these 'moments' are "windows for relational and therapeutic change" (Ansdell et al., 2010, p. 22). At this point it is clear that pivotal moments can relate to musical and non-musical phenomena, and in investigating the unique qualities of pivotal moments within music therapy, the wider fields of psychological therapies, including the psychotherapies, must be examined.

\section{Pivotal Moments in Psychology, Music Psychology and Psychotherapy}

Within the field of psychology there is an interest in 'moments', which seem to be the most meaningful and significant for people's life (Seligman, 2005). Maslow (1962, 1964, 1968, 1976) describes peak experiences as being "moments of pure, positive happiness when all doubts, fears, inhibition, tensions, and weaknesses, are left behind" (1962, p. 9). During a peak experience people usually feel more alive, integrated and in touch with the sacred and there is a complete distortion of time. Maslow concluded that this kind of experience is so powerful that it could affect one's attitude towards life. It is interesting to note that Bruscia (1987) has found that peak experiences are not uncommon in music improvisation: "Within a therapy situation, peak experiences bring hope and encouragement [...] and move the client to forge ahead in therapy" (p. 565).

Similarly to Maslow's description of peak experience, Laski (cited in Amir, 1992) analysed the experience of ecstasy and found that some aspects, which were experienced by people, included loss of time and space, joy, insight and physical sensations. May (cited in Amir, 1992) writes about the Aha! experience as a moment when a person suddenly grasps the meaning of some important event and experiences it as a moment of heightened awareness.

There is a variety of terminology used within psychotherapy to describe pivotal moments. Kramer (1989) sees certain moments, which he describes as a "series of 
moments of engagement separated by less important periods in which the work of therapy seemed to be going well" (p. 13), as breakthroughs in the therapeutic process. Rogers (1980) emphasises that a basic condition for moments of congruence to occur is the authenticity of the therapist, who leads the patient to his own realness and separation.

Natterson (1993) highlights some principles that influence the therapeutic relationship on the creation of turning points, which are defined as "moments in which there are shifts or changes in the patient's behaviour, attitudes, or feelings" ( $p$. 45). Böhm (1992) states that turning points in psychoanalysis can be either the beginning of change or a consolidation of change. Similarly to Terr et al. (2005), Natterson (1993) emphasises that the creation of turning points is affected by the therapist's ability to be empathic.

From another perspective, Stern and Sander conceptualised important stages, which take place in the change process: a) moving along (Stern et al., 1998); b) present or now moments (Stern, 1995); c) moments of meeting (Sander, 1962); and d) an open space (Sander, 1983). As described, now moments are unexpected in timing and they are pregnant with "an unknown future that can feel like an impasse or an opportunity" (Stern et al., 1998, p. 912). In this sense, now moments are like the concept of kairos (Aldridge, 1996). When a therapist and patient explore and experience a now moment, it can become a moment of meeting. In the authors' view, these moments may also derive through a conflict, either between the therapist and the patient (Odell-Miller, 2002) or an inner conflict between the patient's unconscious and reality or his creative and destructive self (Pedersen, 1999; Skyllstad, 2008). Therefore the therapist's qualities of flexibility, intuition and authenticity are important in the creation of these moments.

In summary, most of the authors discuss qualities that enrich the therapeutic relationship, supporting experiences of a deeper understanding and insight. Apparently, the literature review shows a lack of studies and systematic research concerning pivotal moments in improvisational music therapy, although the role of pre-composed classical music in investigating pivotal moments is researched more widely. As far as the authors are aware, there were no studies, which explore pivotal moments in music therapy with people with mental illness prior to our study. 


\section{Methodology-Methods}

The methodology reflects the aim of the study, which was to investigate pivotal moments in music therapy in adult mental health. It was based on a phenomenological qualitative method, as this design was appropriate to examine the questions and focus of the study. To examine pivotal moments the literature regarding pivotal moments from different fields was reviewed, while different terminology was highlighted in order to give a background to similar kind of experiences. From this the research questions arose.

\section{Questions for Investigation}

The main questions of the study were as follows:

1. What are the main characteristics of pivotal moments?

2. Are there any specific aspects that help pivotal moments to emerge?

3. How do pivotal moments affect the patient's process in therapy and life in general?

4. What is the importance of pivotal moments for the music therapist?

Phenomenological Qualitative Study and Interpretative Phenomenological Analysis (IPA)

As the research questions show, we were interested in gaining a deeper understanding of the phenomena and experience of pivotal moments, therefore a phenomenological qualitative method, was an appropriate method to use. Phenomenological inquiry focuses almost entirely on experience, how things seem to the perceiver, while evidence is derived from first-person reports (Ashworth, 2003; Giorgi and Giorgi, 2008; Lawthom and Tindall, 2011). Qualitative study (Edwards, 2012; Guba and Lincoln, 1994; O’ Callaghan, 1996), as an umbrella of methods, is a complex process and it is defined as "a way that human beings study other human beings and the condition of a human being" (Bruscia, 2005, p. 129). As a method of data analysis, we used the Interpretative Phenomenological Analysis (IPA) (Smith, 2004), which provides methodological framework in qualitative, experiential, and psychological research by which to investigate human experience (Pietkiewicz and Smith, 2012; Pothoulaki, MacDonald, \& Flowers, 2012; Smith and Osborn, 2008). IPA has been widely used by music therapists previously (Pool and Odell-Miller, 2011; Smith, Flowers, \& Larkin, 2009; Hervey and Odell-Miller 2013), as well as in 
the evaluation in mental health research (Fortune et al., 2010).

\section{Case Study Presentation}

In order to study how pivotal moments occur in music therapy in mental health, an individual case study with a man with schizophrenia from the music therapist's clinical work is described. "Case study is a well-established research strategy where the focus is on a case in its own right" (Robson, 2011, p. 135). Therefore, case study is specific and particular, complex in its functioning and real-life grounded, as it is related to contemporary events (Smeijsters, 1997; Stake, 1995).

\section{Semi-Structured Interviews}

In addition to the case study, the music therapist conducted semi-structured interviews with three music therapists, who work in mental health. Semi-structured is defined as when "the investigator will have a set of questions or an interview schedule, but the interview will be guided by the schedule rather than being dictated by it" (Smith and Osborn, 2008, p. 58). Semi-structured interviews allow the researcher and the participant to engage in a dialogue in real time. They also give enough space and flexibility for original and unexpected issues to arise, which the researcher may investigate in more detail with further questions (Pietkiewicz and Smith, 2012). Semi-structured interviews were appropriate, in order to guide the participants to discuss their experiences and perceptions in regards to this phenomenon in music therapy. A purposive sample of three was agreed following the criteria: a) the music therapists should have at least five years of experience working in the field of adult mental health; b) the approach that each music therapist applies should be psychoanalytically informed so there is some uniformity; and c) they were willing and available.

Purposive sampling (Wigram, 2005), in line with the theoretical underpinnings of IPA, enabled the music therapist to choose participants who appeared most likely to serve as the best informants for this particular study. The main concern in IPA is to give full appreciation to each participant's account (case). For this reason, samples in IPA studies are usually small, which enables a detailed in depth and thorough caseby-case analysis, leading to rich data sets. Typically, IPA researchers aim for a fairly homogeneous sample (Pietkiewicz and Smith, 2012). Therefore, although the sample 
group was small, the aim was simply "to gain a detailed picture of a respondent's beliefs about, or perceptions or accounts of a particular topic" (Smith, 1995, p. 9). One male and two females who were experienced music therapists participated. There were no apparent diverse features; all had extensive psychoanalytic training and experience as well as over 20 years of music therapy experience. All interviews were recorded and were conducted at times and places chosen by the participants. Each music therapist was interviewed once and all interviews lasted between 20-30 minutes.

A topic guide with the questions, which were divided into four main categories, was prepared. Each part consisted of main questions and prompts. These arose from the literature review and discussion with supervisors and colleagues about the salient aspects needed in the study. During the interviews, the music therapist asked openended questions free from hidden presumptions. Unfortunately, due to the time limit of the study, we did not have the opportunity to conduct follow-up interviews, in order to confirm or elaborate previous discussions. However the final findings were shared with the respondents to confirm authenticity. The main questions of the interviews were as follows:

1. What is your understanding of the meaning of pivotal moments in music therapy?

2. In the music therapy sessions, did the pivotal moments occur during the musicmaking time or during a discussion you had with the patient?

3. How did you perceive the pivotal moment? Were they observable in all cases or did you perceive them through your patient's countertransference?

4. Can you recall a pivotal moment of any of your patients and describe it?

5. How did these pivotal moments affect the patients' lives in general, if at all?

6. How would you summarise the importance of these moments for you as a music therapist, and especially in a mental health setting?

The four categories were agreed as follows:

a. "Meaning and Occurrence of Pivotal Moments" (Questions 1 and 2);

b. "Experience of Pivotal Moments" (Question 3);

c. "Case Study Example and the Role of Music" (Question 4); and

d. "Contribution-Importance of Pivotal Moments" (Questions 5 and 6).

A table (Table 1) with the questions and answers can be found in appendix A. 


\section{Data Analysis}

Following the IPA framework, in the first stage of analysis, all the interviews, including the questions, were transcribed in detail. The anonymity of the participants was retained, so they were referred to as P1, P2 and P3. These codes appear on the Tables 1 and 2 consistently. All the transcriptions were based on a semantic level: all the words spoken, including false starts; significant pauses, laughs and other features, such as posture, facial expression and movement vocabulary, were considered worthy of recording (Smith and Osborn, 2008; Smith et al., 2009). In the second stage of analysis, initial notes, which included some descriptive, linguistic and conceptual comments, were made. Subsequently, a first table (Table 1) was prepared, in which all the questions were included, and by using key words, the themes were developed.

Moving to the third stage, the transcriptions were analysed in more depth and in relation to the first table with the music therapists' aggregated responses, we searched for connections across emergent themes. The outcome of the music therapists' interviews and thematic analysis resulted in fourteen main themes grouped into three theme clusters. The clusters were:
a. Characteristics of pivotal moments;
b. Experience of pivotal moments; and
c. Contribution of pivotal moments.

Then a second table (Table 2) was created, which included conclusions and connections found from the common patterns across the three cases (Appendix B).

\section{Ethical Issues}

The study was approved by the Research Ethics Panel of (Name of the University) University and also the clinical facility. Permission was obtained to use clinical material, and informed consent was obtained from the patient and music therapists taking part in the interviews. Pseudonyms have been used for the participants in the study, and the clinical facility has not been named or linked to the study report. Confidentiality has been maintained. All data and recordings were handled with care and securely saved.

An individual case study with a patient with schizophrenia is now discussed in order to demonstrate the unfolding of a pivotal moment, and its intensity. 


\section{Case Study including a Pivotal Moment with a Man with Schizophrenia}

The role of a pivotal moment was explored through music therapy sessions held with a man with schizophrenia, within an adult mental health setting in England, for 4 months in 2013/2014. The sessions were one-hour long, and they consisted of a pattern of talking - playing music - talking. The case study is based on a real patient and ethical consent was obtained. All main details have been amended for reasons of confidentiality.

\section{Music Therapy Approach}

The approach the music therapist applied was psychoanalytically informed with active music making using improvised and pre-composed material at the centre (Metzner, 1999; Odell-Miller, 2001). In this approach psychoanalytic theory and practice are used in the understanding and thinking of the music therapy process, along with a focus on the exploration of past experiences in the patient's formation of new relationships. The music therapist was especially influenced by Winnicott's idea of holding environment (Winnicott, 1971, 1984) and Bion's theory of containment (Bion, 1962) and their application in music therapy (De Backer, 1993). Concepts such as transference and countertransference (Freud, 1912, 1993; Laplanche and Pontalis, 1973) were considered important to be analysed further, in order to gain a better understanding of the process of the therapy. Bearing in mind the now extensive literature written by modern music therapists on transference and countertransference in music therapy (Pedersen 2006; Davies, Richards and Barwick 2015), including musical countertransference (Odell-Miller 2001), there was also a focus in our reflections, approach and knowledge base, upon how music therapists have drawn upon these psychoanalytic concepts in music therapy.

\section{Diagnosis and Referral}

Peter, a 45 year old man, had been diagnosed with paranoid schizophrenia since his first admission to psychiatric hospital 24 years prior to the referral. As an outpatient he was referred to individual music therapy sessions at the beginning of the 4 month music therapy treatment by a ward nurse in collaboration with the psychiatrist and multi-disciplinary team. The reasons for referral were to improve Peter's mental health through his love for music and help him through a phase of depression after a psychotic episode. 


\section{History and background}

Peter grew up in a wealthy environment. He was sent to a boarding school up to the age of 13 and then to an expensive prestigious college. Schaverien (2015) draws attention to the link between early boarding school experiences and attachment difficulties in her recent research and the attention needed by therapists to take note of this. Peter's parents divorced in a very critical period in his life as an adolescent. During that period, Peter was living with his two cousins and grandmother, who was suffering from depression and could not take care of them appropriately. After the divorce, he stayed with his father, while his siblings moved with their mother and stepfather. According to Bowlby (1979), "there is a strong causal relationship between an individual's experiences with his parents [attachments] and his later capacity to make affectional bonds" (p.135). Therefore, the lack of a secure base and the early insecure attachment to his parents, led to Peter's fear of trusting people and forming new relationships.

Peter had some of the characteristic symptoms of schizophrenia, such as delusions and hallucinations, which stopped when treated by medication. $\mathrm{He}$ attempted many suicides during periods of breakdowns and psychotic episodes. Whilst medication appeared to control some symptoms, Peter still had affective flattening and social withdrawal. He was alcohol-dependent, although he kept a drink diary, and was a heavy smoker. Peter was depressed, restless and had difficulties sleeping. At times he talked and laughed to himself. He found it difficult to concentrate and memorise information. At the time of music therapy, he lived in supported housing and worked as a volunteer for 15 hours each week in a local organisation. He had a supportive social network, and structured social life.

\section{Aims of the Treatment}

Psychoanalytically informed music therapy, could offer Peter an alternative means of communication through improvisation in addition to offering psychological development and reflection. Through music-making and discussion he could find a way to express himself, which helped him deal with unbearable thoughts, and to focus more upon positive aspects in his life. Music therapy could also helped him deal with feelings of shame, through the use of songs, which would enable him to develop his self-esteem and confidence. It was considered important to provide a safe and containing place, in which depressive feelings could be understood and dealt with. 
Lastly, as Peter did not have many choices in his life, the music therapy space could help him take some control, by leading the improvisation and by selecting the songs that he wanted to sing.

\section{Description of the Music Therapy Treatment}

Peter attended 14 weekly sessions, out of the possible 15 , over a period of 4 months. The initial phase of the treatment, which included the first three sessions, is called "establishing the relationship". During these sessions, Peter was feeling very ashamed, highlighting how little he had succeeded in life. He was not ready to play music; he spent a long time in the session listening to improvisation or other piano pieces that the music therapist performed for him. This phase of the treatment proved essential as it helped Peter to feel safe in the therapeutic relationship, and he began to express how helpful he found the music therapist's attentive listening and calm attitude helping him to become less anxious.

The main period for exploration was the middle phase, "dealing with feelings", covering the sessions $4-8$, although the $8^{\text {th }}$ was a missed session. Retrospectively we have also wondered whether this break might link also to the pain described by Schaverien (2015) for the boarding school child, who is constantly experiencing broken attachments and a feeling of being outside the other relationships (outside those at home when at school and vice versa). During this phase, the $7^{\text {th }}$ could be characterised as the "pivotal session" of the treatment. During this period Peter would sing while the music therapist accompanied him on the piano and he was willing to start improvising with her on the piano. The improvisations were mainly led by the themes he would bring for discussion, mainly about his family members and past painful experiences including his delusions and hallucinations, where some interpretations were made.

The final phase, which includes the sessions 9-15, could be characterised as the "beginning of a new life". Peter showed a great change in his demeanour and started to see life from a different perspective. He became aware of his feelings of shame and depression, realising that drinking was associated with loss or the threat of loss. During the sessions he would suggest new songs to sing, and his voice sounded powerful and expressive. Through the sessions Peter was inspired to teach himself how to play the guitar, especially as his concentration improved. Using his new skill, he improvised as the music therapist accompanied him on the flute. 


\section{Selection of Peter's Pivotal Moment}

In the process of selecting the pivotal moment, the music therapist reviewed all the recordings from the sessions and personal and supervision notes. She assessed that the $7^{\text {th }}$ session, was selected as pivotal, as it was the peak of Peter's anxious and depressive feelings, in which containment played a significant role. Peter did not attend the $8^{\text {th }}$ session; and through reflection in supervision we concluded that Peter was vulnerable to changes, and seemed to find the previous session exposing and challenging. Peter's absence in the $8^{\text {th }}$ session, along with his comeback and change from the $9^{\text {th }}$ session, discussed below in more detail, signified the importance of the $7^{\text {th }}$ session, thus leading the music therapist to consider it as the pivotal in the whole treatment.

\section{Analysis of Peter's Pivotal Moment within the Therapy}

The approach used for the case analysis (Aigen, 2005) followed a moment-bymoment description of the sessions and reflections upon these. The video recording of each session was analysed during supervision, drawing emphasis on musical and textual phenomena.

In the $7^{\text {th }}$ session Peter arrived 15 minutes early. He seemed impatient and very anxious. He began by saying how disturbed he was over the news that his father had been diagnosed with cancer. The way he spoke seemed to imply that he felt responsible and blamed himself for the illness. This was in contrast to the more critical attitude towards his father that Peter had previously conveyed in sessions, especially when his father withdrew financial support, in order to help him stop drinking. He expressed his wish to visit his father, but his relationship with his stepmother seemed to be an obstacle. His stepmother had never accepted him, thus not giving him the opportunity to come closer to his father's new family. Later he talked about his parents' relationship and divorce, which had a great impact on him.

Prior to music-making, Peter became upset as he began to recall his memories from hallucinations, that he had over the summer, when he refused to take his medication, which he felt had a negative impact on him. Fear of staying alone resulted in Peter continuously going out drinking, remembering his suicide attempts and wishing he had not survived. He explained that at that point he was so paranoid that he could not separate reality from delusions and hallucinations. Peter and the music therapist associated his drinking behaviour with fear of loss, his girlfriend's suicide 
and the fear of loosing his father. It seemed that Peter would "drink his sorrow" by drinking alcohol, in order to "attack" himself. The music therapist discussed with Peter his self-destructive behaviour, which seemed to be in conflict with his selfdeveloping and creative self, thus not allowing him to express his inner self. Avoiding painful experiences over past sessions, complaining about his lack of achievements, and his reluctance to allow the music therapist to know him better, led them to explore his fears and avoidance of dealing with difficulties.

While listening to Peter talking, the music therapist felt "lost", and her countertransference suggested that he conveyed chaos as a result of absence of containment. The music therapist realised that Peter needed to turn something chaotic into meaning. Having all these thoughts without a thinker could not be usable, but they would remain, as Bion (1962) suggests "Beta elements", which are elements not transformed into symbols, and can neither be remembered nor processed (EgenfeldtNielsen, 2010). Through reverie, Peter was able to talk and transform them, also later through the music-making, into "Alpha elements", which are transformed sensuously perceivable stimuli into elements useful for thinking, dreaming and memory (Bion, 1967) and therefore, he was more capable of dealing with them. When Peter is anxious, his weaker self does not help him understand his experience, but musical reverie could hold him, so that he would become more inclined to reflect. The theories were linked with the case during reflection and discussion in the supervision after the session. However, some of the music therapist's thoughts were further discussed with the patient during the following sessions, when the patient was more able to reflect on difficult issues.

Following this discussion, intuitively, the music therapist started to improvise on the lower register of the piano. She chose to play on a pentatonic mode on the black keys, providing elements of boundaries and freedom at the same time. Peter, sitting next to her on the upper register, was not at all reluctant, as he placed his fingers on the black keys and started to play very softly. Then he closed his eyes. The music therapist's left hand was playing a rhythmic steady pattern, giving a holding element, while her right hand was playing short melodic patterns. Peter's playing was becoming more rhythmic and gradually louder and more confident. He reached a point where he played the same note repeatedly, and aggressively. He was tightening his eyes intensively and the music therapist's heart began to beat fast. Then he opened his eyes, smiled at her and moved on to another note. Peter began to play more freely. 
The base notes were not as loud now, suggesting that the music therapist was there and had survived his unbearable thoughts, containing him, and helping him to move forward. The whole improvisation lasted for five minutes, but seemed longer, due to the intensity of the playing.

Van Camp (in De Backer, 2008) uses the metaphors of "left-hand-role" (bass-line position) and "right-hand role" (descant-line position) to describe aspects of the therapeutic relationship between the music therapist and the patient. The bass-lineposition offered to Peter the supporting, containing and resonating knowing, on a psychological level, through which the descant-line position could lie entirely open and unknown for the patient, as well as for the therapist. Peter's way of playing could be connected to De Backer's (2008) transition from "sensorial play" to musical form by psychotic patients. Initially Peter expressed his conflict during the musical improvisation through "fragmented" playing and then he was able to move on through a "moment of synchronicity" (De Backer, 2008) in the creation of psychic space. Therefore, he could move from the transference into a psychic space and was be able to give form to his traumatic experiences and memories.

Peter characterised the improvisation as "catharsis", an idea that is also reflected by Ansdell (1995) when talking about music as a means for emotional expression. He expressed that he never thought he could play like this. It appeared that his fears were evacuated and contained through music. His whole posture changed and it became apparent how painful it was for him to share these unbearable experiences and thoughts with the music therapist prior to music-making.

\section{Evaluation of the Pivotal Moment and its Contribution}

Rolvsjord (2006) indicates that, "music can clearly be viewed as a form of dynamic force, promoting change, development and growth" (p. 5). The session described as pivotal was very significant for Peter, as it was the most challenging session where Peter was able to share deep, meaningful moments within the music therapy experience. Through the improvisation and reflection, Peter was contained and relieved. The obvious change in his demeanour and thoughts, his outlook on general aspects of life, indicate that he was ready to understand difficult issues.

Peter's pivotal moment contributed also to the music therapist's way of working. This moment was validating, emphasising to her that she could use her skills as a therapist in order to access a patient's painful experience and later contain him. These 
moments indicated that through the therapeutic relationship some aspects, such as trust, intuition and empathy were present, enhancing the therapeutic change.

\section{Interviews: Investigation of Pivotal Moments through Music Therapists' experiences}

Semi-structured interviews with three music therapists were conducted in order to gather data and gain a deeper understanding of the music therapy experience in relation to the pivotal moments. The outcome of the interviews and thematic analysis resulted in fourteen main themes grouped into three theme clusters (Table 2, Appendix B). The theme-based clusters developed from the results of the interview analysis are described below with comments regarding the interview content.

\section{a) Characteristics of Pivotal Moments}

According to the music therapists' responses, pivotal moments seem to have certain characteristics, which derive from the meaning of the term and lead to their recognition. Countertransference is always present in these moments (P1, P2 and P3); therefore they can be identified as pivotal. Moreover, countertransference can resonate with a therapist's life event (P1). Therefore, countertransference helps the music therapists to perceive the pivotal moments and changes in the patient's state when changes are not observable.

Another characteristic of pivotal moments is that they can contain significant and emotionally important aspects (P1 and P2). A pivotal moment is not an intellectual one, as it usually includes an emotional aspect perceived or felt by both the patient and the therapist or an acknowledged emotional content on behalf of the therapist.

Furthermore, P2 and P3 stated that an obvious change or a shift always takes place. Interestingly, P1 who did not refer directly to a shift, acknowledged this concept but described it as 'reverie', a retrospective recognition of pivotal moments.

All of the music therapists stated that pivotal moments could occur both in musicmaking time and in discussion. The interviewees reported that in psychoanalytically informed music therapy pivotal moments could occur equally as important in the talking part with patients who can think, interpret and reflect. Moreover, pivotal moments could equally occur during the time elapsed from the transition from music to discussion, as for example a gesture or a look. 
The type of music does not appear to have any particular significance, as improvised music (P1, P2 and P3), as well as pre-composed pieces (P1 and P2) could underpin pivotal moments at the same level depending upon the significant meaning in the moment of the musical process.

\section{b) Experience of Pivotal Moments}

Pivotal moments are not always observable or perceived by both the patient and the therapist. In the cases where the pivotal moment was obvious, all participants noticed aspects that included a change in the patient's body language, demeanour or feelings. Other aspects included transformation of a very flat and affectless person to a lively person (P1), a change from an entirely negative to a sensitive, more selfconfident and thoughtful person (P2) and change of demeanour through the release of energy (P1 and P2), for example hitting the gong and the cymbal aggressively.

Pivotal moments could be either positive or negative. Although the interviewed music therapists spoke mostly as if they are positive, they do not have to be, especially when linked to an 'acceptance'. Other examples included a conflict about the therapy's effectiveness, which eventually led to powerful moments (P2).

During pivotal moments, the therapists seem to hold their patient's state by containment, reverie and intuition (P1, P2 and P3). Therefore, the therapist's capacity to deal with the 'here and now' is considered vital. Reverie, both musical and non musical, can be related to the countertransference as a mechanism of recognising the pivotal moments.

\section{c) Contribution of Pivotal Moments}

Pivotal moments seem to have an important contribution both to the therapist's way of working and to the patient's life. In all of the examples described by the interviewees, the patient showed emotional change, along with other changes, after a pivotal moment. According to the music therapists, pivotal moments lead to a better understanding of the patient, and they move forward to the therapeutic process.

Moreover, pivotal moments affect the patient's life in different domains. All of the music therapists denoted that the patients, through the process of the therapy and the contribution of the pivotal moment, felt that they had achieved something, accepted another side of themselves and furthermore might have improved their relationship with others. 
The music therapists summarised the significance of pivotal moments for their practice as "nodal points" (P1 and P2), which are important for showing the change and "unconscious processes" that they are not, usually consciously aware of, although they are around all the time. Finally, all interviewees agreed that the moments are fundamental, exciting, creative, illuminating and validating for a therapist.

\section{Discussion of Findings and Conclusions}

The study set out to investigate pivotal moments in music therapy in mental health. Therefore, the findings from the interviews, along with the case study and the existing literature discussed previously, following a process of triangulation, will be discussed together and conclusions drawn.

\section{Question 1: What are some of the characteristics of the pivotal moments?}

Pivotal moments seem to display distinctive characteristics concerning different therapies. However, features that are present during pivotal moments in music therapy specifically, are the alteration of time perception and the capacity to deal with 'here and now', the emotional aspect of the experience through verbal and musical expression, and the view that a pivotal moment could be either a positive or negative experience.

\section{Distortion of time - 'Here and Now'}

Robbins and Forinash (1991) and Priestley (1975) describe experiences in which time seems suspended in musical sharing between the therapist and the patient. Grocke's (1999a) research highlights the possibility of time altering experiences within music therapy, while Maslow $(1962,1964,1968,1976)$ emphasises that during

peak experiences there is a complete distortion of time. This experience was evident through music therapy sessions with Peter, as the improvisation during the pivotal moment felt longer than it actually lasted, due to the intensity of the playing.

Another important aspect is the therapists' capacity to deal with 'here and now', as described by Odell-Miller (2002) and Pedersen (1999) in the literature. The importance of 'here and now' in the therapy is acknowledged in all the interviews, and it was also discussed in the case study presentation. 


\section{Emotionally charged experiences}

Pivotal moments in GIM are described as emotional and embodied experiences (Grocke, 1999a; Lin et al., 2010; Marr, 2001). All of the interviewees clearly stated that one of the characteristics of pivotal moments is that they can contain significant and emotionally important aspects. Similarly, the experience of the music therapist with Peter showed that the pivotal moment was emotionally charged for both of them, also a conclusion by Pedersen (2006).

\section{Positive and negative experiences}

Maslow (1962) characterises peak experiences as "moments of pure, positive happiness" (p. 9), whereas, Grocke (1999a) differently, discovered that negative emotions, such as fear and anger, could also be experienced within pivotal moments. Moments of conflict (Odell-Miller, 2002; Pedersen, 1999; Skyllstad, 2008) may be considered as negative, which once recognised and understood in relation to the patient, can then lead to a positive change.

All three interviews supported Grocke's opinion by suggesting that pivotal moments could be either positive or negative. Furthermore, in the case study it was evident that Peter was led to the pivotal moment through a very painful and exposing discussion about unbearable experiences and thoughts. There was also a noticeable conflict between his destructive and creative self. However, his experience of the pivotal moment had a positive outcome, as he was contained, felt relieved, was able to reflect, and then was able to move forward.

\section{Question 2: Are there any specific aspects that help pivotal moments to emerge?}

The specific aspects that help pivotal moments to emerge fall into two broad categories: (a) the role of music and (b) the role of the therapist.

\section{a) The role of music}

Grocke (1999b), through musical analysis, found that classical pieces with structured musical form were most often underpinning pivotal moments. Trondalen (2005), although discussing clinical improvisation, concludes, similarly to Grocke (1999b), that during significant moments the music had a predictable form. Ruud (1998) concludes that improvisational music therapy may lead people to change. 
It was clear from the interviews that both improvised music and pre-composed music could provoke pivotal moments at the same level. In the music therapy session described with Peter, the pivotal moment occurred during a clinical improvisation, through which, in the therapist's opinion, the patient's state was met and matched. This was also commented on as an important feature by interviewees in terms of recognition of a patient who is seen and understood in these moments of change.

\section{b) The role of the therapist}

The role of the therapist during pivotal moments is crucial, and is dependent upon the therapist's qualities, and the basic features or techniques that the therapist is able to apply during therapy. Terr et al. (2005) and Rogers (1980), emphasise that a basic condition in the creation of moments in therapy is the authenticity of the therapist, along with the therapist's qualities of flexibility and intuition. Natterson (1993) highlights that the creation of turning points is affected by the therapist's ability to be empathic, while Welch (2005) refers to key qualities such as trust and confidence. One important aspect reflected through discussion with the interviewees, is the capacity of the therapist for intuition and empathy, along with the ability to maximize the conditions for reverie and readiness to accept the change.

During pivotal moments, all of the interviewees emphasise that they hold their patient's state by containment, thus acknowledging the significance for a therapist to contain and hold something that might be quite important for the patient. These opinions are supported through material described about Peter's pivotal moment. Firstly, the therapist was able to hold his emotional state when expressing unbearable thoughts, and later contain him through improvisation, which led him to change.

According to Terr et al. (2005), an important therapeutic principle is when the therapist helps the patient to understand his fantasy, which, in the authors' view, can be considered as analogous of Bion's (1962) concept of reverie, which was also referred to intensively by one of the interviewees (P1). Finally, very important aspects are considered to be transference and countertransference. Prado (cited in Grocke, 1999a) referred to moments of change in therapy where there is a moment of "a climax of transference situations" (p. 48). According to the interviewees, countertransference is always present in these moments. Therefore, it helps music therapists to perceive the pivotal moments and alterations in the patient's state when changes are not observable. Similarly, the music therapist's countertransference in the 
case with Peter was trusted in order to lead to a clinical improvisation, through which the patient became more able to tolerate his intellectual and emotional chaos. Pedersen (2006) found that music therapists' countertransference understanding when choosing significant music moments of change, was affected by resonance with their own life events, but it is not clear from our study whether this is the case although one participant mentioned this factor.

\section{Question 3: How pivotal moments affect the patient's process in therapy and life in general?}

\section{Therapeutic progress}

Ansdell et al. (2010) characterise moments as "windows for relational and therapeutic change" (p. 22), while Bruscia (1998) states that peak experiences during improvisation "move the client to forge ahead in therapy" (p. 565). Ellenberger (cited in Amir, 1992) suggests that moments of insight and realisation in therapy are creative and often transformative of both the patient and the therapist. This was evident from the interviewees, who referred to the change of the process of the therapy and the patient's behaviour after a pivotal moment. All of the music therapists agreed that without pivotal moments or without the capacity to create new moments, the therapy would not lead anywhere.

\section{Life changing experiences}

Amir (1992) and Maslow (1962, 1964, 1968, 1976) support that, moments of transformation are so powerful that they could affect one's attitude towards life. Böhm (1992) argues that turning points can be either the beginning of change or a consolidation of change. According to Ellenberger (cited in Amir, 1992), "the whole personality is restructured" (p. 119), while Natterson (1993) states that in some cases "there are shifts or changes in the patient's behaviour, attitudes, or feelings" (p. 45).

In the cases described in the interviews, all participants noticed aspects that included a change in the patient's body language, demeanour or feelings. After the pivotal moment, some of the patients made links with other circumstances in their lives, while in other cases the patients gained recognition about an aspect of themselves, and felt that they had achieved something. This was also evident through the final phase of the music therapy treatment of Peter in the case study presentation. 


\section{Question 4: What is the importance of pivotal moments for the music therapist?}

Amir (1992) in her research concluded that all of the therapists considered that these moments contributed to a better understanding of their work, of themselves as human beings, and to their own growth. The music therapist interviewees summarised the significance of pivotal moments for their practice as "nodal points", which are important for showing the change. They stated that it could be validating and very important for the therapist to sense those moments. Finally, they described the moments as fundamental, exciting, creative and illuminating for a therapist.

\section{Trustworthiness of the Study}

As the investigator and music therapy trainee involved in this study, the music therapist found it challenging at times to have "no expectations". It was also important to remain flexible with the clinical work. Although the study was investigating pivotal moments, the music therapist did not seek to provoke the "moment" in the therapy, but she remained focused on her patient's progress and therapeutic aims.

In gathering experiences from music therapists in adult health through semistructured interviews, the music therapist was fully prepared that their answers would not fall into similar categories and she was careful not to influence the manner and content of their answers. All the interviews were transcribed in detailed and further discussed in academic supervision, and chosen sections validated, in order to ensure the trustworthiness of the interviews.

\section{Strengths and Limitations of the Study}

One of the strengths of this study is that information was gathered not only about pivotal moments, but also for other "moments" as a similar kind of experience, not only in music therapy, but in other therapies as well. Moreover, themes discussed in the literature review were supported by relevant examples collected via a case study and the interviews. The authors point to strengths of the study in empowering music therapists to focus not only upon outcomes and changes in symptoms which can be measured, but also upon in depth narrative material and personal history which can be linked to pivotal moments. Unfortunately, owing to ethical procedures and the time limit of the study, the music therapist did not have the opportunity to work with more than one individual case. The findings cannot therefore be easily generalised, however 
from the in-depth material from the one case study and three interviews, indications can be made and conclusions drawn.

\section{Suggestions for Future Research}

As seen through the discussion, pivotal moments are of great importance for both the patients and the therapists. The authors would suggest future research on the investigation of pivotal moments in mental health through gathering more detail of the patients' experiences linked to that of the music therapists with more subjects involved. Furthermore, it would be very interesting to explore the emergence of pivotal moments in groups, where different aspects might contribute in addition to the complexity of the group work. The study reveals a lack of this type of research for people with schizophrenia and also points to a gap in specific trainings which music therapists might develop in the future specifically for this population.

\section{Conclusion}

The aim of the study was to investigate pivotal moments in music therapy in adult mental health. Pivotal moments are described as "turning points" where the patient understands an issue or problem from another perspective. These may lead to further change outside the therapy setting. In searching for answers to the main questions for investigation, the study was aiming to deepen the understanding of the nature of the experience of these moments in music therapy, by showing some of their characteristics and their significance. Whilst it is a small study, and any significant conclusions need to be considered with caution, the study adds to the case orientated qualitative research and clinical literature on the subject. The study offered a theoretical frame as an essential tool for the therapeutic space, albeit using a specifically improvisation focussed psychoanalytically informed music therapy approach formulated in the UK, but results will be of interest internationally owing to the in-depth nature of the material. It is hoped that the study can influence practitioner music therapists to consider the likely conditions that might lead to pivotal moments, including enabling more awareness and consciousness of the reach of these moments. Further research is encouraged as pivotal moments are of great importance in the music therapy field for the recovery rehabilitation and well being of participants. 


\section{Acknowledgments}

We would like to acknowledge thanks to the patient and the team within the mental health service. Moreover, we would like to thank the music therapist interviewees, who were willing to participate in the study and share their valuable experiences. 


\section{References}

Aigen, K. (2005). Writing the qualitative research report. In: B. L. Wheeler (Ed.), Music Therapy Research, Second Edition (pp. 210-225). Gilsum, NH: Barcelona Publishers.

Aldridge, D. (1996). Music therapy research and practice in medicine: From out of the silence. London: Jessica Kingsley Publishers.

Amir, D. (1992). Awakening and expanding the self: Meaningful moments in the music therapy process as experienced and described by music therapists and the music therapy clients (Doctoral thesis, New York University). Retrieved from http://steinhardt.nyu.edu/scmsAdmin/media/users/jts390/Dissertations/AmirDorit 1992.pdf

Amir, D. (1996). Experience music therapy: Meaningful moments in the music therapy process. In: M. Langenberg, K. Aigen and J. Frommer (Eds.), Qualitative music therapy research beginning dialogues (pp. 109-130). Gilsum, NH: Barcelona Publishers.

Amir, D. (1999). Tales from the therapy room. In: J. Hibben (Ed.), Inside music therapy: Client experiences (pp. 267-276). Gilsum, NH: Barcelona Publishers.

Amir, D. (2001). Layers of meaning. Nordic Journal of Music Therapy, 10(2), 209220.

Ansdell, G. (1995). Music for life: Aspects of creative music therapy with adult clients. London: Jessica Kinglsey Publishers.

Ansdell, G., Davidson, J., Magee, W. L., Meehan, J., and Procter, S. (2010). From

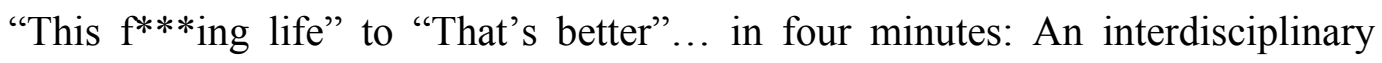
study of music therapy's "present moments" and their potential for affect modulation. Nordic Journal of Music Therapy, 19(1), 3-28.

Ashworth, P. (2003). An approach to phenomenological psychology: the contingencies of the lifeworld. Journal of Phenomenological Psychology, 34(2), 145-156.

Bion, W. R. (1962). Learning from experience. London: Karnac Books.

Bion, W. R. (1967). Second thoughts. London: Karnac Books.

Böhm, T. (1992). Turning points and change in psychoanalysis. International Journal of Psychoanalysis, 73, 675-684.

Bowlby, J. (1979). The making and breaking of affectional bonds. London: Tavistock. 
Bruscia, K. E. (1987). Improvisational models of music therapy. USA: Charles C. Thomas Publisher.

Bruscia, K. E. (1998). Defining music therapy. $2^{\text {nd }}$ Edition. USA: Barcelona Publishers.

Bruscia, K. E. (2005). Designing qualitative research. In: B. L. Wheeler (Ed.), Music therapy research (pp. 129-137). $2^{\text {nd }}$ Edition. Gilsum: Barcelona Publishers.

Carr, C., Odell-Miller, H. and Priebe, S. (2013). A systematic review of music therapy practice and outcomes with acute adult psychiatric in-patients. PLOS ONE, 8(8), doi:10.1371/journal.pone.0070252.

Davies, A., Richards, E. and Barwick, N. (2014). Group music therapy: a group analytic approach. New York: Routledge.

De Backer, J. (1993). Containment in music therapy. In: M. Heal and T. Wigram (Eds.), Music therapy in health and education (pp. 32-39). London: Jessica Kingsley Publishers.

De Backer, J. (2008). Music and Psychosis: A Research Report Detailing the Transition from Sensorial Play to Musical Form by Psychotic Patients. Nordic Journal of Music Therapy, 17(2), 89-104.

DSM-5 $5^{\mathrm{TM}}$ (2013). Diagnostic and Statistical Manual of Mental Disorders. $5^{\text {th }}$ Edition. USA: American Psychiatric Association.

Edwards, J. (2012). We need to talk about epistemology: Orientations, meaning, and interpretation within music therapy research. Journal of Music Therapy, 49, 372394.

Egenfeldt-Neilsen, F. (2010). Attention and Creation: Growth in the vertices of $W . R$. Bion. London: Karnac Books.

Fachner, J. (2014). Communication change - Meaningful moments, situation cognition and music therapy: A response to North (2014). Psychology of Music, 42(6), 791-799.

Fortune, Z., Rose, D., Crawford, M., Slade, M., Spence, R., Mudd, D., Moran, P. (2010). An evaluation of new services for personality-disordered offenders: Staff and service user perspectives. International Journal Social Psychiatry, 56, 186195.

Freud, S. (1912) The Dynamics of Transference. In R. Langs (Ed.), (1990) Classics in Psychoanalytic Technique. New Jersey: Jason Aronson Inc. [A reprint from The Standard edition of the Complete Psychological works of Sigmund Freud, 12, 
The Institute of PsychoAnalysis, The Hoggarth Press Ltd., and (for U.S. rights) Basic Books Inc.]

Freud, S. (1993), Observations on transference-love: Further recommendations on the technique of Psycho-Analysis III. The Journal of Psychotherapy Practice and Research, 2(2), 171-180.

Giorgi, A., and Giorgi, B. (2008). Phenomenology. In: J. A. Smith (Ed.), Qualitative psychology: A practical guide to research methods (pp. 26-52). $2^{\text {nd }}$ Edition. London: Sage Publications.

Gold, C. (2007). Music therapy improves symptoms in Adults hospitalised with schizophrenia. Evidence-Based Mental Health, 10(3), 77.

Gold, C., Heldal, T.O., Dahle, T. and Wigram, T. (2005). Music therapy for schizophrenia-like illnesses. The Cochrane Database of Systemic Reviews. Retrieved from http://onlinelibrary.wiley.com/doi/9.1002/14651858.CD004025.pub2/abstract

Gold, C., Solli, H. P., Krüger, V., Lie, S. A. (2009). Dose-response effect for music therapy for people with serious mental disturbances. Systematic review and metaanalysis. Clinical Psychology Review, 29, 193-207.

Grocke, D. (1999a). A phenomenological study of pivotal moments in guided imagery and music (GIM) (Unpublished doctoral thesis), Faculty of Music, The University of Melburne, Australia.

Grocke, D. (1999b). Pivotal moments in guided imagery and music. In: J. Hibben (Ed.), Inside music therapy: Client experiences (pp. 295-306). Gilsum, NH: Barcelona Publishers.

Grocke, D. (1999c). The music which underpins pivotal moments in Guided Imagery and Music. In: T. Wigram and J. De Backer (Eds.), Clinical applications of music Therapy in psychiatry (pp. 197-211). London: Jessica Kingsley Publishers.

Grocke, D. (2005). A case study in the Bonny Method of Guided Imagery and Music (BMGIM). In: D. Aldridge (Ed.), Case study designs in music therapy (pp. 97117). London: Jessica Kingsley Publishers.

Guba, E. G. and Lincoln, Y. S (1994). Competing Paradigms in Qualitative Research. In N. K. Denzin, and Y. S. Lincoln (Eds.). The Landscape of Qualitative Research. Theories and Issues (pp. 105-117). London, Thousand Oaks: Sage

Hervey, P. and Odell-Miller, H. (2013). Containment or contamination?: Music therapy, personality disorder and the forensic mental health team. In: S. J. 
Compton Dickinson, H. Odell-Miller and J. Adlam (Eds.), Forensic music therapy: a treatment for men and women in secure hospital settings (pp. 205229). London: Jessica Kingsley Publishers.

Jampel, P. (2006). Performance in music therapy with mentally ill adults (Unpublished doctoral dissertation), Steinhardt School of Education, New York University.

Kramer, P. D. (1989). Moments of engagement: Intimacy psychotherapy in a technological Age. USA: W. W. Norton \& Company.

Laplanche, J., and Pontalis, J. B. (1973). The Language of Psycho-Analysis (D. Nicholson-Smith, Trans.). London: Karnac and the Institute of Psycho-analysis.

Lawthom, R., and Tindall, C. (2011). Phenomenology. In: P. Banister (Ed.), Qualitative methods in psychology: A research guide (pp. 3-21). $2^{\text {nd }}$ Edition. Maidenhead: McGraw-Hill/Open University Press.

Lin, M., Hsu, M., Chang, H., Hsu, Y., Chou, M., and Crawford, P. (2010). Pivotal moments and changes in the Bonny Method of Guided Imagery and Music for patients with depression. Journal of Clinical Nursing, 19, 1139-1148.

Longman Dictionary of Contemporary English (2009). $5^{\text {th }}$ Edition. Harlow: Pearson/Longman.

Marr, J. (2001). The effects of music on imagery sequence in the Bonny Method of Guided Imagery and Music (GIM). The Australian Journal of Music Therapy, 12, $39-45$.

Maslow, A. H. (1962). Lessons from the peak experience. Journal of Humanistic Psychology, 2, 9-18.

Maslow, A. H. (1964). Religions, values, and peak-experiences. London: Penguin Books.

Maslow, A. H. (1968). Toward a psychology of being. $3^{\text {rd }}$ Edition. USA: John Wiley $\&$ Sons.

Maslow, A. H. (1976). The farther reaches of human nature. London: Penguin Books.

McCaffrey, T., Edwards, J., and Fannon, D. (2011). Is there a role for music therapy in the recovery approach in mental health? The Arts in Psychotherapy, 38, 185189.

Metzner, S. (1999). Psychoanalytically informed music therapy in psychiatry. In: T. Wigram and J. De Backer (Eds.), Clinical applications of music therapy in psychiatry (pp. 102-118). London: Jessica Kingsley Publishers. 
Mohammadi, A. Z., Minhas, L. S., Haidari, M., and Pannah, F. M. (2012). A study of the effects of music therapy on negative and positive symptoms in schizophrenic patients. The German Journal of Psychiatry. Retrieved from www.gjpsy.unigoettingen.de

Mössler, K., Assmus, J., Heldal T. O., Fuchs, K., and Gold, C. (2012). Music therapy techniques as predictors of change in mental health care. The Arts in Psychotherapy, 39, 333-341.

Natterson, I. (1993). Turning points and intersubjectivity. Clinical Social Work Journal, 21(1), 45-55.

NICE Guidelines (National Institute for Clinical of Excellence) (2014). Psychosis and schizophrenia in adults: Treatment and management. Great Britain: The British Psychological Society and The Royal College of Psychiatrists.

O'Callaghan, C. (1996). The relative merits of qualitative and quantitative research approaches in music therapy. Australian Journal of Music Therapy, 7, 28-36.

Odell-Miller, H. (1991). Group improvisation therapy: The experience of one man with schizophrenia. In: K. Bruscia (Ed.), Case studies in music therapy (pp. 418431). Gilsum, NH: Barcelona Publishers.

Odell-Miller, H. (2001). Music therapy and its relationship to psychoanalysis. In: Y. Seale and I. Streng (Eds.), Where analysis meets the arts (pp. 127-152). London: Karnac Books.

Odell-Miller, H. (2002). One man's journey and the importance of time: Music therapy in an NHS mental health day centre. In: A. Davies and E. Richards (Eds.), Music therapy and group work: Sound company (pp. 63-75). London: Jessica Kingsley Publishers.

Oxford Dictionary. Moment / Momentum. Retrieved from http://www.oxforddictionaries.com/definition/english/moment

Pedersen, I. N. (1999). Music therapy as holding and re-organizing work with schizophrenic and psychotic patients. In: T. Wigram and J. De Backer (Eds.), Clinical applications of music therapy in psychiatry (pp. 24-43). London: Jessica Kingsley Publishers.

Pedersen, I. N. (2006). Countertransference in music therapy: A phenomenological study on counter transference used as a clinical concept by music therapists working with musical improvisation in adult psychiatry (Doctoral thesis, Aalborg University, Denmark). Retrieved from 
http://vbn.aau.dk/files/70261290/inp_2007.pdf.

Pedersen, I. N. (2014). Music therapy in psychiatry today - Do we need specialization based on the reduction of diagnosis-specific symptoms or on the overall development of patients' resources? Or do we need both?. Nordic Journal of Music Therapy, 23(2), 173-194.

Pool, J., and Odell-Miller, H. (2011). Aggression in music therapy and its role to creativity with reference to personality disorder. The Arts in Psychotherapy, 38, 169-171.

Pothoulaki, M., MacDonald, R. and Flowers, P. (2012). An Interpretative Phenomenological Analysis of an improvisational music therapy program for cancer patients. Journal of Music Therapy, 49(1), 45-67.

Priestley, M. (1975). Music therapy in action. London: Constable.

Priestley, M. (1994). Essays on analytical music therapy. Phoenixvill, PA: Barcelona Publishers.

Pietkiewicz, I. \& Smith, J.A. (2012). Praktyczny przewodnik interpretacyjnej analizy fenomenologicznej w badaniach jakościowych w psychologii. Czasopismo Psychologiczne, 18(2), 361-369. [English version: A practical guide to using Interpretative Phenomenological Analysis in qualitative research psychology]

Robbins, C., and Forinash, M. (1991). A time paradigm: Time as a multilevel phenomenon in music therapy. Music Therapy, 10(1), 46-57.

Robson, C. (2011). Real world research. $3^{\text {rd }}$ Edition. Chichester: Wiley.

Rogers, C. R. (1980). A way of being. Boston: Houghton Mifflin.

Rolvsjord, R. (2006). Whose power of music? A discussion on music and powerrelations in music therapy. British Journal of Music Therapy, 20(1), 5-12.

Ruud, E. (1998). Music therapy: Improvisation, communication and culture. Gilsum, NH: Barcelona Publishers.

Sander, L. (1962). Issues in the early mother-child interaction. Journal of the American Academy of Child and Adolescent Psychiatry, 1(1), 141-166.

Sander, L. (1983). Polarity, paradox and the organisational process in development. In: J. Call (Ed.), Frontiers of infant psychiatry (pp. 333-346). New York: Basic Books.

Schaverien, J. (2015). Boarding school syndrome: The psychological trauma of the "privileged" child. London: Routledge.

Schizophrenia Research Institute (2013). About Schizophrenia. Retireved from 
http://www.schizophreniaresearch.org.au/schizophrenia/about-schizophrenia/

Seligman, M. E. P. (2005). Positive psychology, positive prevention, and positive therapy. In: C. R. Snyder and S. J. Lopez (Eds.), Handbook of positive psychology (pp. 3-8). Oxford: Oxford University Press.

Skyllstad, K. (2008). Managing conflicts through music: Educational perspectives. In: O. Urbain (Ed.), Music and conflict transformation: Harmonies and dissonances in geopolitics. United States: I. B. Tauris \& Co Ltd.

Smeijsters, H. (1997). Multiple perspectives: A guide to qualitative research in music therapy. Gilsum, NH: Barcelona Publishers.

Smith, J. A. (1995). Semi-structured interviewing and qualitative analysis. In: J. A. Smith, R. Harré, and L. Van Langenhove (Eds.), Rethinking methods in psychology (pp. 9-26). London: Sage Publications.

Smith, J. A. (2004). Reflecting on the development of interpretative phenomenological analysis and its contribution to qualitative research in psychology. Qualitative Research in Psychology, 1, 39-54.

Smith, J. A., Flowers, P., and Larkin, M. (2009). Interpretative phenomenological analysis: Theory, method and research. London: Sage Publications.

Smith, J. A., and Osborn, M. (2008). Interpretative phenomenological analysis. In: J. A. Smith (Ed.), Qualitative psychology: A practical guide to research methods (pp. 53-80). $2^{\text {nd }}$ Edition. London: Sage Publications.

Solanki, M. S., Zafar, M., and Rastogi, R. (2013). Music as a therapy: Role in psychiatry. Asian Journal of Psychiatry, 6, 193-199.

Stake, R. E. (1995). The art of case study research. Thousand Oaks, CA: Sage Publications.

Stern, D., Sander, L. W., Nahum, J. P., Harrison, A. M., Lyons-Ruth, K., Morgan, A. C., Bruschweilersten, N., and Tronick, E. Z. (1998). Non-interpretative mechanisms in psychoanalytic therapy: The "Something more" than interpretation. The International Journal of Psychoanalysis, 79, 903-921.

Stern, D. (1995). The Motherhood Constellation. New York: Basic Books.

Stern, D. (2004). The present moment in psychotherapy and everyday life. New York: W. W. Norton \& Company.

Terr, L. C., McDermott, J. F., Benson, R. M., Peter, B. J., Deeney, J. M., Rogers, R. R., and Zrull, J. P. (2005). Moments in psychotherapy. Journal of American Academy of Child and Adolescent Psychiatry, 44(2), 191-198. 
Trondalen, G. (2005). "Significant moments" in music therapy with young persons suffering form anorexia nervosa. Music Therapy Today, VI(3), 396-429 (online). Retrieved from http://www.MusicTherapyWorld.net.

Unkefer, R. F. (1990). Music therapy in the treatment of adults with mental disorders: Theoretical bases and clinical interventions. New York: Schirmer Books.

Van Camp, J. (1999). Reflections on music in music therapy. In: T. Wigram and J. De Backer (Eds.), Clinical applications of music therapy in psychiatry (pp. 265-268). London: Jessica Kingsley Publishers.

Welch, M. (2005). Pivotal moments in the therapeutic relationship. International Journal of Mental Health Nursing, 14, 161-165.

Wigram, T. (2005). Survey research. In: B. L. Wheeler (Ed.), Music therapy research (pp. 272-281). $2^{\text {nd }}$ Edition. Gilsum, NH: Barcelona Publishers.

Winnicott, D. W. (1971). Playing and reality. London: Routledge.

Winnicott, D. W. (1984). The maturational processes and the facilitating environment. London: Karnac Books.

World Health Organisation (WHO) (2016). Mental Disorders. Retrieved from http://www.who.int/mediacentre/factsheets/fs396/en/ 